九州大学学術情報リポジトリ

Kyushu University Institutional Repository

\title{
A Modification Of Ekdahl's Method For Routing Floods Through Reservoirs
}

Kumagai, Saizo

Research Institution of University Forests, Faculty of Agriculture, Kyushu University

https://doi.org/10.5109/22624

出版情報：九州大学大学院農学研究院紀要. 9 (2)，pp.203-207，1949-05. Kyushu University バージョン：

権利関係 : 
Journal of the Faculty of Agriculture, Kyūshū University, Vol. 9, No. 2

May 31,1949

\title{
A MODIFICATION OF EKDAHL'S METHOD FOR ROUTING FLOODS THROUGH RESERVOIRS
}

\author{
SaIzo Kumagai
}

1.

In a previous paper(1) we suggested a nomographic solution of Ekdahl's equation in the problem of reservoir storage. Later it came to our notice that the idea had been anticipated by Prof. Chesley J. Posey, who had proposed a slide-rule solution, referring to the construction of an alignment chart as an alternative procedure. ${ }^{(2)}$ The question naturally arises: Is it possible to construct a similar slide-rule based on any other formula than Ekdahl's? The answer is in the affirmative, though the statement must be made with a mental reservation. In the present note we shall show that, by using a parabolic formula of integration instead of the trapezoidal, we can set up an analogue to Ekdahl's equation, which permits the same treatment as the latter.

2.

Let the equation of continuity be

$$
\frac{d V}{d t}=\backslash Q(t)-q(V)
$$

where $t$ denotes the time, $V$ the storage, $Q(t)$ the rate of inflow, $q(V)$ the rate of "outflow.

Then

$$
V_{2}-V_{1}=\int_{t_{1}}^{t_{2}} Q(t) d t-\int_{t_{1}}^{t_{2}} q(V) d t
$$


where the subscripts 1 and 2 refer to the beginning and end of the time interval respectively. If in the evaluation of the second integral in (2), we approximate $q(V)$ by a polynomial of degree $m+n+1$ in $t$, making $m$-th order contact with $q(V)$ at $t=t_{1}$ and $n$-th order contact at $t=t_{2}$, we get an algebraic or a transcendental equation, from which, given the value of $V_{1}, V_{2}$ may be determined. Thus if we take $m=0, n=0$, we have the Ekdahl formula :

$$
V_{2}+\frac{h}{2} q\left(V_{2}\right)=V_{1}-\frac{h}{2} q\left(V_{1}\right)+\int_{t_{1}}^{t_{2}} Q(t) d t,
$$

$h$ representing $t_{2}-t_{1}$.

If we take $m=1, n=0$, we obtain

$$
\begin{aligned}
V_{2}+\frac{h}{3} q\left(V_{2}\right)=V_{1}-\frac{2}{3} h q\left(V_{1}\right)+\frac{h^{2}}{6} q^{\prime}\left(V_{1}\right) q\left(V_{1}\right)-\frac{h^{2}}{6} q^{\prime}\left(V_{1}\right) Q\left(t_{1}\right) \\
+\int_{t_{1}}^{t_{2}{ }^{\prime}} Q(t) d t .
\end{aligned}
$$

For let $q(V)$ in (1) be approximated by a polynomial of the second degree in $t$ :

$$
p(t)=a_{0}+a_{1} t^{\prime}+a_{2} t^{2},
$$

were $a_{0}, a_{1}, a_{2}$, are undetermined coefficients.

The conditions to be fulfilled by $p(t)$ are:

$$
\begin{aligned}
& q\left(V_{1}\right)=p\left(t_{1}\right)=a_{0}+a_{1} t_{1}+a_{2} t_{1}{ }^{2}, \\
& q^{\prime}\left(V_{1}\right)(d V / d t)_{1}=p^{\prime}\left(t_{1}\right)=a_{1}+2 a_{2} t_{1}, \\
& q\left(V_{2}\right)=p\left(t_{2}\right)=a_{0}+a_{1} t_{2}+a_{2} t_{2}{ }^{2},
\end{aligned}
$$

where $(d V / d t)_{1}$ denotes the value of $d V / d t$ at $t=t_{1}$.

Hence

$$
q\left(V_{2}\right)-q\left(V_{1}\right)=a_{1}\left(t_{2}-t_{1}\right)+a_{2}\left(t_{2}^{2}-t_{1}^{2}\right),
$$

or

$$
\frac{q\left(V_{2}\right)-q\left(V_{1}\right)}{t_{2}-t_{1}}=a_{1}+a_{2}\left(t_{2}+t_{1}\right) .
$$

By subtraction we get

$$
\frac{q\left(V_{2}\right)-q\left(V_{1}\right)}{t_{2}-t_{1}}-q^{\prime}\left(V_{1}\right)(d V / d t)_{1}=a_{2}\left(t_{2}-t_{1}\right) .
$$

On the other hand, $p^{\prime}\left(t_{2}\right)-p^{\prime}\left(t_{i}\right)=2 a_{2}\left(t_{2}-t_{1}\right)$.

Eliminating $a_{2}$ between the last two equations, we obtain 


$$
p^{\prime}\left(t_{2}\right)-p^{\prime}\left(t_{1}\right)=2\left\{\frac{q\left(V_{2}\right)-q\left(V_{1}\right)}{t_{2}-t_{1}}-q^{\prime}\left(V_{1}\right)\left(d V / d t_{1}\right\}\right.
$$

Hence, having regard to equation (1), we find by the EulerMaclaurin formula

$$
\begin{gathered}
\int_{t_{1}}^{t_{2}} q(V) d t \risingdotseq \int_{t_{1}}^{t_{2}} p(t) d t=\frac{t_{2}-t_{1}}{2}\left\{p\left(t_{2}\right)+p\left(t_{1}\right)\right\}-\frac{\left(t_{2}-t_{1}\right)^{2}}{12}\left\{p^{\prime}\left(t_{2}\right)-p^{\prime}\left(t_{1}\right)\right\} \\
=\frac{t_{2}-t_{1}}{3}\left\{2 q\left(V_{1}\right)+q\left(V_{2}\right)\right\}+\frac{\left(t_{2}-t_{1}\right)^{2}}{6} q^{\prime}\left(V_{1}\right)\left\{Q\left(t_{1}\right)-q\left(V_{1}\right)\right\}
\end{gathered}
$$

Substitution of this expression for the second integral in (2) yields formula (4).

Now the reason why (3) is adapted for numerical calculation is that it is of the form:

$$
A\left(V_{2}\right)=B+C\left(V_{1}\right)
$$

in which $A(V)$ and $C(V)$ can be represented graphically, once the value of $h$ is fixed; and $B$ is a quantity whose values are computable beforehand. It is these properties of (3) that enable us to solve it conveniently with the aid of numerical tables, or graphs, or a slide-rule, or alternatively, a nomogram with three parallel straight supports.

Turning to equation (4), we see it also assumes a similar form:

$$
A^{\prime}\left(V_{2}\right)=B^{\prime}+C^{\prime}\left(V_{1}\right) \text {, }
$$

where $B^{\prime}$ stands for $-h^{2} q^{\prime}\left(V_{1}\right) Q\left(t_{1}\right) / 6+\int_{t_{1}}^{t_{2}} Q(t) d t$. Here $A^{\prime}(\boldsymbol{V}), C^{\prime}(V)$ are of the same nature as $A(V), C(V)$, but $B^{\prime}$ is determined only after the value of $V_{1}$ is found. This difference between $B$ and $B^{\prime}$, however, does not preclude us from applying to (4) the various devices enumerated above.

We shall illustrate the use of equation (4) by a numerical example.

3.

Suppose a stream issues from a reservoir which is fed by torrential waters. Assuming that the inflow rate varies linearly with the time $(t)$, and the outflow rate as the square of the head

* The remainder term in this formula is found to be $-\left(t_{2}-t_{1}\right)^{1}\left(d^{3} q(V) / d t^{3}\right)_{i} / 72$ $t_{1}<\xi<t_{2}$. 
$(z)$, and that the surface area $(F)$ of the reservoir remains constant, the equation of continuity may be written:

$$
F \frac{d z}{d t}=a t+b-k z^{2}
$$

where $a, b, k$ are constants. This equation is integrable in terms of modified Bęssel functions of orders $\pm 1 / 3$ and their derivatives.

Expanding these functions in power series, we get the general integral :

$$
\begin{aligned}
& z=\left\{C\left(\frac{1}{\alpha \bar{k}^{-}}+\frac{\alpha}{3} \tau^{3}+\frac{\alpha^{3} k}{3 \cdot 4 \cdot 6} \tau^{6}+\frac{\alpha^{5} k^{2}}{3 \cdot 4 \cdot 6 \cdot 7 \cdot 9} \tau^{9}+\frac{a^{7} k^{3}}{3 \cdot 4 \cdot 6 \cdot 7 \cdot 9 \cdot 10 \cdot 12} \tau^{12}+\cdots\right)\right. \\
& \left.\left.+\frac{a}{2} \tau^{2}+\frac{a^{3} k}{2 \cdot 3 \cdot 5} \tau^{5}+\frac{a^{5} k^{2}}{2 \cdot 3 \cdot 5 \cdot 6 \cdot 8} \tau^{8}+\frac{a^{3} k^{3}}{2 \cdot 3 \cdot 5 \cdot 6 \cdot 8 \cdot 9 \cdot 11} \tau^{11}+\cdots\right)\right\} /\left\{C \tau \left(1+\frac{a^{2} k}{3 \cdot 4} \tau^{3}\right.\right. \\
& \left.+\frac{a^{4} k^{2}}{3 \cdot 4 \cdot 6 \cdot 7} \tau^{5}+\frac{x^{6} k^{3}}{3 \cdot 4 \cdot 6 \cdot 7 \cdot 9 \cdot 10} \tau^{3}+\frac{a^{3} k^{4}}{3 \cdot 4 \cdot 6 \cdot 7 \cdot 9 \cdot 10 \cdot 12 \cdot 13} \tau^{12}+\cdots\right) \\
& \left.+1+\frac{\alpha^{2} k}{2 \cdot 3} \tau^{3}+\frac{\alpha^{4} k^{2}}{2 \cdot 3 \cdot 5 \cdot 6} \tau^{6}+\frac{\alpha^{6} k^{3}}{2 \cdot 3 \cdot 5 \cdot 6 \cdot 8 \cdot 9} \tau^{9}+\frac{\alpha^{8} k^{4}}{2 \cdot 3 \cdot 5 \cdot 6 \cdot 8 \cdot 9 \cdot 11 \cdot 12} \tau^{12}+\cdots\right\},
\end{aligned}
$$

where $\tau=a t+b, \alpha=1 / F a$, and $C$ denotes the integration constant.

Suppose a flood flow sets in, the rate of inflow increasing from zero at $t=0$ to a peak of $240 \mathrm{~m}^{3} / \mathrm{sec}$ at $t=12$ (in hours), and thence decreasing to zero at $t=28$. Measuring $z$ in meters and taking $k=50 \mathrm{~m} / \mathrm{sec}, F=5 \times 10^{6} \mathrm{~m}^{2}$, we may write equation (5) thus:

$$
\frac{5 \times 10^{6}}{3600} \frac{d z}{d t}=a t+b-50 z^{2}
$$

where $a=20, b=0$ for $0 \leqq t \leqq 12 ; a=-15, b=420$ for $12 \leqq t \leqq 28$.

The factor $1 / 3600$ is introduced to express the rate of change of the head in $\mathrm{m} / \mathrm{sec}$, so that in applying formula (6) we have to adopt $5 \times 10^{6} / 3600$ as the value of $F$.

If we assume $z=0$ when $t=0$, we have $C=0$ for $0 \leqq t \leqq 12$. Hence $z$ works out at 0.953259 when $t=12$. From this second condition we get $C=-0.0030158$ for $12 \leqq t \leqq 28$.

To adapt formula (4) to our problem, we change the dependent variable from $V$ to $z$ by the relation $d V=f(z) d z$, where $f(z)$ denotes the surface area of the reservoir. Then equation (4) in the modified form reads 


$$
\begin{gathered}
V\left(z_{2}\right)+\frac{h}{3} q\left(z_{2}\right)=V\left(z_{1}\right)-\frac{2}{3} h q\left(z_{1}\right)+\frac{h^{2}}{6} \frac{q^{\prime}\left(z_{1}\right)}{f\left(z_{1}\right)} q\left(z_{1}\right)-\frac{h^{2}}{6} \frac{q^{\prime}\left(z_{1}\right)}{f\left(z_{1}\right)} Q\left(t_{1}\right) \\
+\int_{t_{1}}^{t_{2}} Q(t) d t
\end{gathered}
$$

In our example $V(z)=\left(5 \times 10^{6} / 3600\right) z, Q(t)=a t+b, q(z)=50 z^{2}$, $q^{\prime}(z)=100 z$, so that, if we take $h=4,\left(4^{\prime}\right)$ becomes

$$
\begin{aligned}
z_{2}+0.048 z_{2}^{2}= & 0.00072 \int_{t_{1}}^{t_{2}}(a t+b) d t+z_{1}-0.096 z_{1}^{2} \\
& -0.00013824 z_{1}\left(a t_{1}+b-50 z_{1}^{2}\right) .
\end{aligned}
$$

We teproduce in the second column of the accompanying table the successive values of $z$ found by solving this equation repeatedly. The computations have been carried out with the help of the graphs of $z+0.048 z^{2}$ and $z-0.096 z^{2}$

$\begin{array}{rccc}t & \begin{array}{c}z \\ \text { from }\end{array}(6) & \begin{array}{c}z \\ \text { from }\left(4^{\prime \prime}\right)\end{array} & \begin{array}{c}z \\ \text { from }(3)\end{array} \\ 0 & 0 & 0 & 0 \\ 4 & 0.115 & 0.115 & 0.114 \\ 8 & 0.458 & 0.449 & 0.444 \\ 12 & 0.953 & 0.953 & 0.942 \\ 16 & 1.356 & 1.357 & 1.351 \\ 20 & 1.483 & 1.488 & 1.492 \\ 24 & 1.435 & 1.435 & 1.441 \\ 28 & 1.257 & 1.256 & 1.262\end{array}$

The values of $z$ thus computed agree, with one exception, satisfactorily with the corresponding figures in the first column, which represent the values of $z$ as calculated from (6). For comparison the figures obtained by Ekdah's method with the same value of $h$ are given in the third column. In this case, too, the calculations have been carried out semi graphically.

As a general rule, our method is superior to Ekdahl's in point of accuracy, for which advantage we pay the price of performing the intermediate computation of $-h^{2} q^{\prime}\left(\boldsymbol{z}_{1}\right) \boldsymbol{Q}\left(t_{1}\right) / 6 f\left(\boldsymbol{z}_{1}\right)$. Whether or not this price is reasonable is a question with which we are not concerned here.

\section{REFERENCES}

(1) Saizo Kumagai : Butletin of the Kyushu Imperial University Forests, 15, 115 1947).

(2) Chesley J. Posey: Engineering News-Record, 580, April 18 (1935). 